\title{
La perversión de lo privado: violencia e incesto en Malas Juntas, Óxido de Carmen y Los vigilantes ${ }^{1}$
}

\section{The Perversion of the Privacy: Violence and Incest in Malas Juntas, Óxido de Carmen and Los Vigilantes}

\author{
Nicolás Román \\ Centro de Estudios Culturales Latinoamericanos (CECLA), U. de Chile \\ neroman@uc.cl
}

\section{Resumen}

En la dictadura, la irracionalidad y la violencia repercutieron en la construcción de la intimidad de los habitantes del país. El desarrollo de los mecanismos de persecución y ejecución de los disidentes atentó contra las formas de sociabilidad, generando una opacidad en las relaciones sociales. En distintos relatos se buscan los elementos que pervierten la construcción de la subjetividad y transforman la intimidad en dispositivos torcidos de la vida privada. A partir de José Leandro Urbina, Ana María del Río y Diamela Eltit se hará un análisis que liga la corrupción de los vínculos de parentesco y la distorsión de la casa como el refugio frente a las agresiones del régimen.

Palabras clave: violencia, incesto, novelas de la dictadura, parentesco.

\section{Abstract}

Pending the dictatorship the deployment of irrationality and violence, in different ways, impact the construction of the intimacy of the inhabitant of Chile. The systematic development of persecution and execution of the dissidents attempted against the sociability, generating opacity in the social relationship and desire. In different stories, it will search the pervert elements that construct that subjectivity, wich had been transformed the intimacy in twisted devices of private life. From Jose Leandro Urbina, Ana María del Río and Diamela Eltit: this analysis will make a link between corruption of the kinship with the distortion of the conception of the house like a refuge.

Keywords: Violence, Incest, Novels of the Dictatorship, Kinship.

1 Artículo desarrollado en el Seminario "Novelas de la dictadura", dirigido por el Dr. Grínor Rojo, ${ }^{\text {er }}$ semestre de 2012 en la Universidad de Chile. 
La convulsión social provocada por la dictadura y sus agentes no solo removió los cimientos de la sociabilidad pública, sino que también es posible postular que las relaciones familiares se vieron conmocionadas. Este es el caso del cuento "El Amuleto" de José Leandro Urbina, la novela Óxido de Carmen de Ana María del Río y la novela Los vigilantes de Diamela Eltit. La casa como lugar de representación de lo familiar se ve fuertemente afectada por la irrupción de la violencia, descomponiendo los vínculos afectivos y generando relaciones perversas. El incesto y la endogamia están presentes en los relatos como una forma de expresar la transformación negativa de las relaciones de parentesco. El incesto, en este caso, es entendido según el diccionario de la Real Academia española como una "Relación carnal entre parientes dentro de los grados en que está prohibido el matrimonio", considerando según la misma fuente la endogamia como la "práctica de contraer matrimonio [entre] personas de ascendencia común”. Ambas situaciones contravienen los postulados de la antropología del parentesco, que constituye las reglas de la sociabilidad a través de la prohibición del incesto y la alianza fruto de la exogamia. A su vez el psicoanálisis con la función del Edipo también proscribe el incesto a través de la mediación fálica, que tiene por resultado la inserción del sujeto en la vida social y la adquisición del lenguaje.

La perversión de los afectos, con la transgresión de ambos dispositivos, propone una crisis subjetiva, que no solo está relacionada con las estructuras superficiales de la sociedad, sino con sus propias bases. Sin embargo, estos recursos no implican la disolución de los vínculos, sino que, como señala Grínor Rojo a propósito de Las malas juntas, estos son índices:

De que lo único que los acontecimientos históricos hicieron fue hacer que se fuera al fondo lo que estaba en la superficie y que saliera a la superficie lo que estaba en el fondo. Porque la "cosa" estaba ahí desde antes. Los ángeles no se convirtieron de la noche a la mañana en demonios, ni los demonios en ángeles (13).

De esta manera, la exposición del incesto y la endogamia representan una crisis que traspasa los espacios de lo público y lo privado, sin hacer que este último espacio se vea incólume respecto de las responsabilidades de las atrocidades del período dictatorial ${ }^{2}$.

2 Con esto se quiere expresar que no existe una justificación ni explicación de corte "psicológico" de la violencia desplegada en el período en cuestión. Incluso, es posible que la misma haya sido invocada desde lo más íntimo de la sensibilidad reaccionaria. 
Los relatos puestos en relación articulan, todos, de diferente manera relaciones de parentesco pervertidas. En el caso de José Leandro Urbina, en el cuento "El amuleto", un muchacho huye donde su abuela, mientras su padre ha sido preso por el régimen dictatorial. En la casa de ella se reúne con una tía que oficia de delatora de su propia familia: "El sonido de su voz [...] susurra en el teléfono [...] le dice a una imaginable oreja obscena, pegada húmedamente al auricular, que aquí está el otro, el escapado. Le gime que pueden venir, pero le ruega que tengan respeto por la casa de su madre" (37). En este relato, las alusiones sensuales respecto de la tía y la develación de su rol en la detención del padre demuestran cómo, de un día para otro, los que se pretendían ángeles se volvieron demonios.

El caso es diferente con las novelas de Ana María del Río y Diamela Eltit. La trama de ambas se desarrolla en dos casas claustrofóbicas que evidencian la tensión al interior de la relaciones familiares. El incesto y la endogamia es evidente en el caso de Óxido de Carmen que relata la relación amorosa de dos medios hermanos (Carmen y el narrador, ambos hijos de un padre ausente militar), tal como lo refleja una escena de la aproximación erótica entre los adolescentes: "Me puso la mano en el vientre, adentrándose con su pasmosa fiereza bajo mi camisa, mientras me bañaba en horror delicioso" (37). Por el contrario, la relación perversa no es percibida a primera vista en Los vigilantes: "Las miradas que nos vigilaban apabullantes y sarcásticas no pueden ya alcanzarnos. Alcanzarnos. Mamá y yo nos acercamos extasiados mientras yo olvido mi hambre por su cuerpo, mi deseo de fundir mi carne con la suya" (Eltit 129). La libido del hijo, en este último caso, tiende a la fusión con la madre para satisfacer su estado carente, no obstante, en este último pasaje se descarta aquella posibilidad que se mantuvo vigente en la trama del relato con la constante alusión a la falta en la díada madre-hijo.

La constitución familiar irregular por la ausencia del padre y el empoderamiento fálico de la madre -a través del uso de la escritura- hacen que las posiciones subjetivas heredadas del psicoanálisis, en la novela de Diamela Eltit, sean puestas aparentemente en jaque. En otras palabras, la madre se mide en los mismos términos con el padre en la disputa epistolar, sin embargo, su irreverencia frente a él se quiebra con la constante alusión a la precariedad generalizada del hogar y la vida hegemonizada por la supervisión del hijo, quien viene a ser una proyección masculina que sobrelleva la castración de la madre protagonista.

La fusión afectiva no se consuma como un incesto, como en los relatos anteriores, pero sí evidencia la perversión de las relaciones familiares debido a la agobiante dinámica de cartas que mantienen los padres, sumándose a la compleja enunciación del hijo como sujeto larvario que vive al amparo de su progenitora como si estuviera dentro de su propio cuerpo. 


\section{III}

Peter Sloterdijk en su trilogía Esferas, pondera el espacio de la intimidad como el lugar de las relaciones intersubjetivas. Estos vínculos se establecerán de diferentes maneras, teniendo el denominador común que las esferas presentan una barrera inmunológica para quien quisiera irrumpir en su interior. Sin embargo, la casa y la familia como fronteras de inmunidad en las novelas analizadas serán descartadas como espacios de refugio: "La situación familiar no existe desligada de un contexto socio-histórico que contribuye a construir la subjetividad, [...] no es una creación separada y autónoma sino que está imbricada en un contexto social con el que está en permanente intercambio (Lagos, familia 207). La familia ha desajustado su consideración de refugio. A su vez la casa en las tres novelas se convierte en un espacio intervenido.

En Las malas juntas, el poder dictatorial ha llegado hasta la casa del protagonista del relato y lo ha desalojado de su lugar de residencia: "Hace una semana que allanaron nuestra casa y que se llevaron a mi padre y mis hermanos. Yo, de pura suerte, me escapé por los tejados y vine a refugiarme donde mi abuela" (33). La frontera de protección que ofrecía la casa se ha difuminado con la irrupción de la violencia. En Óxido de Carmen la casa será un escenario alegórico de la implementación del poder y la persecución por medio de la Tía Malva: "La casa donde transcurre prácticamente todo Óxido de Carmen está viva - personificada- y tiene un papel activo, pues funciona en contra de algunos de sus habitantes; es una cárcel en miniatura que transforma en objetos comestibles a las personas que se introducen en ella" (Gómez Castellano, Rodeada 247). En el caso de la novela de Ana María del Río el poder se recrudecerá y se volverá hacia adentro: “Toda la casa está llena de su presencia, de ojos, de orejas sueltas, oyendo lo que se pueda de malo. Tuerce las frases como la lana. La amargura es muy venenosa y se pega" (33). La vigilancia se exacerba luego de que ha quedado en evidencia que los adolescentes mantienen una relación amorosa. Los espacios privados se van clausurando durante el desarrollo de las novelas.

En el caso de Los vigilantes el poder de custodia hace que el proceso de observación y persecución atraviese las esferas de lo público y lo privado. Por fuera están los vecinos y por dentro está la madre del padre. La ubicuidad del poder se inmiscuye por todas partes: "No sé quién eres, pues estás en todas partes, multiplicado en mandatos, en castigos, en amenazas que rinden honores a un mundo inhabitable" (112). La casa ya no sirve de refugio subjetivo y la familia es el reverso de una sociabilidad en crisis generalizada. La incapacidad de establecer los vínculos sociales primarios es una réplica en escala de la impotencia de recomponer el pacto social quebrado por el golpe de Estado.

Las relaciones sociales replegadas en los ámbitos privados se corrompen con el incesto y la endogamia, construyendo un veto a lo público. La relación afectiva claustrofóbica no se construye haciendo un vínculo con un tercero, sino que se proyecta en los vínculos de contigüidad y repliegue. La relaciones sociales ya no se 
despliegan para construir lo público mediante un pacto comunicativo, sino que se repliegan para satisfacer el deseo "en lo no mediado" del ámbito familiar directo. En otras palabras, sin prohibición del incesto no existe la alianza política, ni las distinciones de la cultura y el lenguaje.

\section{IV}

La casa es el espacio donde los sujetos son condenados a poner en escena su deseo y recrear su vida social. Lo público en la década de los sesenta fue un campo en disputa, que posterior al golpe fue invadido por diversas formas de violencia. Sin embargo, el ámbito privado no resultó ser el refugio frente a la agresión: "La casa protege al soñador, la casa nos permite soñar en paz. No son únicamente los pensamientos y las experiencias los que sancionan los valores humanos" (Bachelard 37). En dictadura lo establecido en la Poética del espacio queda sancionado. La casa se envuelve en la crisis, y -como alegoría de la vida nacional- se ve aprisionada en las redes de la violencia.

La casa, refugio del soñador, no es tratada en las novelas como el espacio íntimo donde la subjetividad se recompone en las imágenes idealizadas del primer contacto con el mundo. Los sueños representan el deseo carente de mediación, condensan en imágenes de la vigilia la energía pulsional y la despliegan en la emergencia de las fuerzas del inconsciente:

La mayoría de mis sueños tienen que ver con una mujer que me espera semidesnuda en el segundo piso de una casa desconocida. Yo voy subiendo despacio la escalera y la veo, casi de lado [...] Al principio me costaba que pudiera tener ese sueño, sobre todo que las cosas no andan bien como para tener sueños de ese tipo. Después me fue gustando (Urbina 34).

La fantasía del joven prófugo del cuento "El amuleto" es percibida como un desajuste de acuerdo con el ambiente desolador de la época. Sin embargo, el sueño tiene algo de premonición, porque al llegar la tía a la casa de la abuela, ella es presentada constantemente como un objeto de deseo prohibido:

Ella se vuelve y me mira boquiabierta, como una niña sorprendida en un juego reprochable [...] Ella se estremece y trata de deshacerse de mi brazo, pero yo no la dejo y, aunque dudo un momento, meto mi mano libre en su entrepierna y me agarro a su mata de pelo rizo y me quedo allí, porfiando con su sexo apretado (Urbina 37).

Anteriormente, la tía ha roto el vínculo familiar con la delación del hermano y llega a la casa para perpetuar la captura del sobrino. Ahora ella es víctima del despliegue del apetito inconsciente del sujeto prófugo. El ultraje es una réplica del orden social desmoronado, la imagen de la mujer de los sueños se reitera en la captura del sexo prohibido. 
Sin embargo, en esta transgresión no hay una confirmación de una ruptura positiva del orden del deseo. Este ha sido quebrado anteriormente con la puesta en opacidad de las relaciones familiares. La respuesta del sobrino antes de fugarse de la casa de la abuela, después del ultraje, es irreverente: "Marta comienza a gruñir, insolente, a sollozar, soy tu tía. Sin mirarla, yo sé cómo está, cómo me odia, por eso me detengo, le muestro mi mano, y estiro hacia ella mis dedos pegajosos del licor robado que me acompañará" (Urbina 37). El sujeto le refrenda a su víctima el ultraje y la condena a la humillación.

El desenlace positivo de la escena está abortado de antemano debido a que la venganza no reconstruye el vínculo social. El despliegue de las fuerzas subterráneas de la pulsión incestuosa no regenera las relaciones sociales, puestas en un punto de no retorno debido a la irrupción y confirmación de la violencia onírica del deseo. La irrupción de la violencia en el ámbito social es correlación de la ausencia de una mediación efectiva por medio de acuerdos comunicativos. Finalmente, el pacto social quebrado por el golpe reemplaza las relaciones del orden liberal por las del exterminio: "La eliminación de los cuerpos aparece ligada a una realidad alternativa, un desborde o una crisis de la realidad, y a la postulación de un mundo alternativo, más o menos real que el mundo presente, un sueño". (Giorgi, Sueños de exterminio 4). El exterminio y el sueño tienen un punto en común: la suspensión del principio de realidad y la puesta en escena de la satisfacción de la pulsión. El sueño barre los códigos de la realidad y los sumerge en la condición distorsionada de las imágenes oníricas.

Incesto, sueño y exterminio generan una relación perversa que distorsiona los vínculos sociales y los deja en una puesta en abismo. Se hace difícil pensar en acuerdos intersubjetivos estribados sobre las bases de la inmediatez de la pulsión, puesto que ella no distingue, sino que condensa sus objetos en la proyección de imágenes. El incesto y el sueño, implican una incapacidad de generar desplazamientos elaborados en función de la abstracción metafórica, otorgándoles a la relaciones de contigüidad la energía vinculante. En otras palabras, las relaciones endogámicas no implican una alianza política con un tercero, donde haya una mediación de carácter social. El repliegue del deseo hacia vínculos intrafamiliares condensan la estructura social, imposibilitando la capacidad de nombrar el vínculo de parentesco, como por ejemplo, "soy el amante de mi tía: hijo-cuñado de mi padre, sobrino-cónyuge de mi tía, tío de mí mismo", como ocurriría en caso del cuento "El amuleto".

\section{V}

En Óxido de Carmen las relaciones incestuosas concuerdan con la claustrofobia propuesta por la clausura de lo público. El caserón laberíntico hace que el fuego amoroso entre el narrador y la protagonista sea la condena a muerte de la mujer adolescente. María Inés Lagos percibe la propuesta de la perversión amorosa como: 
Inquietante y enigmátic[a]. Por un lado los lectores deseamos que el apasionado amor entre el narrador y su media hermana escape a la mirada censora de la tía, pero por otro anticipamos que este tipo de amor es imposible pues las relaciones incestuosas son universalmente condenadas. La pareja que antes de la llegada de la Tía Malva vivía en un especie de paraíso, presenta ciertos rasgos míticos de leyenda fundacional (Lagos, Familia 212).

El móvil amoroso de los protagonistas se presenta inquietante, pero también condenado al fracaso. La única salida positiva para esta relación sería el mito de carácter fundacional. No obstante, la percepción del deseo de los protagonistas en la novela esta permeada por la irrupción del mal y la perversión: "Sus ojos trepándose por las fisuras de cualquier cosa prohibida" (10). Incluso la declaración de amor trae implícita su condena: "La amé sin pensar en el horrible pecado que significaba" (10). Por lo tanto, las barreras de protección de lo paradisíaco no son precisamente las que contienen la cartografía del deseo de los jóvenes.

La relación envilecida no es mítica -y si lo fuera- la contención de su violencia originaria se descargaría por alguno de sus márgenes. La violencia es la escena de la crisis:

La adscripción del incesto a la lógica del ensayo comienza ya a mostrar su pertinencia con sólo recordar que en todas las culturas que lo codifican, es siempre el objeto de una prohibición, sumada a otras prohibiciones, y que, en esas mismas culturas, según las tesis de René Girard, cuando ellas viven precisamente graves momentos de "crisis", de rápida acumulación de violencia, las prohibiciones, entre ellas la del incesto, pueden ser transgredidas ritualmente como una manera de salir de la "crisis", lo que significa renovar la cultura, refundarla (Morales 140).

De acuerdo con René Girard, para salir de la crisis es necesario acudir a la transgresión como un suplemento que dilataría la tensión contenida en la sociedad.

La expiación por medio de la transgresión implica una desviación de la violencia por medio de un chivo expiatorio cuya eliminación no genera culpa, puesto que la culpa sería la evidencia de la falta: "El aliento de ella hierve y es hondo pozo de jazmín, orquídea podrida”(27). Sin embargo, en Óxido de Carmen, siempre la retórica del deseo reitera la transgresión como envilecimiento y no como superación. La eliminación de Carmen, suspende al protagonista (y el proceso de escritura) en un paréntesis alucinatorio: "La pérdida de confianza en el poder del lenguaje se marca en su encierro entre paréntesis, comillas y puntos suspensivos, dibujos simbólicos de otra prisión, la del lenguaje" (Gómez Castellano 258). El protagonista es incapaz de edificar la realidad por medio de las palabras y no percibe la secuencia lógica de ellas debido a que se detiene en la contemplación de la imagen de su objeto de deseo que lo invade posteriormente a su muerte: "Mi técnica, mi tic, mi vida, es mirar disimulado hacia el Escape [...] donde me observa Carmen burlona" (Del Rio 66). El 
deseo por Carmen deja al personaje sumido en la alucinación y en la incapacidad de investir libidinalmente un nuevo objeto. La fuerza del deseo por su hermana marcó la incapacidad de salir de la maraña de su pulsión incestuosa.

\section{VI}

La transgresión de las leyes del deseo propuesta por los relatos no es una superación de las condiciones de la violencia desplegada por el aparato dictatorial. La violencia misma estaba contenida en la falsa conciencia de la división entre ángeles y demonios. El incesto y la endogamia implican la crisis de la cultura en el ámbito público y el privado. La saturación de la vida nacional con la violencia hizo que no existiera un reducto no contaminado para la regeneración de los vínculos sociales. Se clausura el acceso a lo público y se corrompe la experiencia de lo privado.

Los vínculos endogámicos y el incesto son la confirmación de la incapacidad de relacionarse con elementos externos a la inmediatez familiar. Esto genera un bloqueo de los factores derivados del complejo de Edipo, que permiten "Aparecer al sujeto deseante, objeto de una pulsión genital que está sometida a la ley de prohibición del incesto y que lo lanza a las relaciones en el campo de la cultura”. (Braunstein 59). Las relaciones endogámicas son el fracaso mismo de la cultura frente a su negación. La perversión del deseo replegado por el gusto de lo mismo hace proliferar un sujeto preso de lo inmediato, que no desea en función del lenguaje y la mediación.

La capacidad de perversión de la violencia en el ámbito del deseo logra generar una prohibición de la diferencia, debido a que en el incesto y en la endogamia no hay una preferencia subordinada al deseo del Otro. En otras palabras, con la preferencia por la perversión no existe la posibilidad siquiera de generar cultura y lenguaje para salir de la inmediatez de la pulsión. Los relatos tienen como significante prohibido la emergencia del otro como diferencia, de ahí la nula figuración de los espacios externos a la casa.

El asalto de la vida pública por medio de los procesos de ejecución y persecución política y la perversión de los espacios privados, dejan en crisis a la cultura. El golpe fustigó "la realidad" y la traspasó con la puesta en escena de su deseo de exterminio, tal como si fuera un sueño, donde la pulsión aniquila con sus imágenes la posibilidad de establecer el lenguaje.

Aunque, tal vez, el protagonista de "El amuleto" de José Leandro Urbina puede fugarse de la realidad podrida luego de perpetuar la humillación, conteniendo la violencia en su huida. Se lleva consigo la violencia, pero pierde la posibilidad de ser un sujeto en las ruinas de la sociedad. Traspasa la pared del fondo y se escabulle por los patios de las casas, tal vez si entrara en cualquiera de sus puertas hubiese implicado nuevamente adentrarse en las sombras de la perversión. 


\section{Referencias}

Bachelard, Gastón. La poética del espacio. México: FCE, 2012. Medio impreso.

Braunstein, Néstor. La re-flexión de los conceptos de Freud en la obra de Lacan. México: Siglo XXI, 1987. Medio impreso.

Del Río, Ana María. Óxido de Carmen. Barcelona: Ediciones del Bronce, 1998. Medio impreso.

Diccionario Real Academia Española $22^{\circ}$ edición. www.rae.es. Sitio web.

Eltit, Diamela. Los Vigilantes. Santiago: Sudamericana, 1999 Medio impreso.

Giorgi, Gabriel. Sueños de exterminio. Buenos Aires: Beatriz Viterbo, 2004. Medio impreso.

Gómez Castellano, Irene. "Rodeada de puntos suspensivos: los usos del espacio en Óxido de Carmen de Ana María del Río”. Revista Iberoamericana, 24 (2008). 222. Medio impreso.

Lagos, María Inés. "Familia, sexualidad y dictadura en Óxido de Carmen de Ana María del Río”. Inti. Revista de Literatura hispánica Número (1994). 40-41. Medio impreso.

Morales, Leonidas. “Diamela Eltit: el ensayo como estrategia narrativa”. Atenea (2004). 490. Medio impreso.

Rojo, Grínor. "Las malas juntas de José Leandro Urbina. Edición completa y definitiva”. Las malas juntas. Santiago: Lom, 2012. Medio impreso.

Urbina, José Leandro. "El amuleto". Las malas juntas. Santiago: Lom, 2012. Medio impreso.

Recibido: 12 septiembre 2013

Aceptado: 15 mayo 2013 